\title{
Acceptability of donor breastmilk banking among health workers: a cross-sectional survey in Zimbabwean urban settings
}

Dexter T. Chagwena ${ }^{1,2^{*}}$ (D), Felistas Mugariri ${ }^{3}$, Bhekimpilo Sithole ${ }^{2}$, Steady Faith Mataga ${ }^{4}$, Ruvimbo Danda ${ }^{5}$, Tonderayi M. Matsungo ${ }^{3}$ and Charles C. Maponga ${ }^{1}$

\begin{abstract}
Background: The World Health Organization (WHO) recommends that donor human milk is superior to artificial infant formula in situations where the baby cannot feed on the mother's breastmilk. The purpose of this study was to determine the acceptability of donor human milk banking among health workers in Zimbabwean urban settings.

Methods: A cross sectional study was conducted among 535 health workers and 15 key informants. Three referral hospitals were purposively selected and systematic random sampling was used to select the health workers. The study was conducted between October 2017 and October 2018.

Results: The concept of donor human milk banking was acceptable among health workers. One-third (31\%) of the study participants reported that they would accept donor breastmilk for their children while $56 \%$ of them would encourage their clients to donate breastmilk. Acceptance of donor human milk banking was associated with a high level of knowledge on breastmilk banks $(p=0.009)$ and the study participants' health profession $(p=0.001)$. Clinical staff were more receptive to donor human milk banking compared to non-clinical health workers. Donor human milk banking was not associated with religion ( $p=0.498)$ or marital status $(p=0.714)$.

Conclusions: The results showed that health workers and policy informers would accept the establishment of breastmilk banks subject to resource availability. Commitment to the establishment of breastmilk banks was moderately acceptable among opinion leaders responsible for spearheading health and nutrition policies.
\end{abstract}

Keywords: Breastmilk banks, Knowledge, Health workers, Breastfeeding, Urban setting, Zimbabwe

\section{Background}

The WHO recommendation that donor breastmilk is the next best option when mother's own milk is unavailable has highlighted the concept of donor breastmilk banking in developing countries [1-4]. However, successful implementation of donor human milk (DHM) banks in settings with high HIV prevalence has been

\footnotetext{
* Correspondence: tungadex@gmail.com

'School of Pharmacy, College of Health Sciences, University of Zimbabwe, Harare, Zimbabwe

${ }^{2}$ Nutri@ctive Zimbabwe, 96 Golden Stairs Rd, Mt Pleasant, Harare, Zimbabwe Full list of author information is available at the end of the article
}

questionable especially when compounded by cultural issues. In countries where DHM banks have been successfully established the crucial role played by health workers to ensure acceptability and success of DHM banks has been stressed $[5,6]$.

Breastfeeding benefits both the child and the mother resulting in improved future intelligence, economic development and reduced mortality [7-12]. Breastmilk, whether mother's own milk or DHM, is viewed as superior to infant formula even in HIV prevalent areas [1, 13, 14]. In instances where breastfeeding is not possible, either breastmilk substitutes or donor breastmilk is 
required. WHO recommends the use of infant feeding options that are culturally acceptable to ensure optimal health for the child [15]. Zimbabwe reports high breastfeeding rates, with $98.1 \%$ of children breastfed at some point before reaching 24 months [16]. Exclusive breastfeeding (EBF) is currently estimated at $61 \%$ and efforts to encourage EBF are mainly advanced through the Baby-Friendly Hospital Initiative (BFHI) and community-based infant and young child feeding (IYCF) promotion led by the Ministry of Health and Child Care [17, 18].

The country follows the universal WHO recommendations for all infants despite HIV status of the mother of exclusive breastfeeding for 6 months, followed by the introduction of nutritious adequate complementary foods and continued breastfeeding for 24 months or beyond $[13,19,20]$. Where breastfeeding is not possible, infant formula is usually the alternative infant-feeding option in spite of the campaign for EBF within the initial 6 months of life [18]. Common cases of low birth weight, premature births, and orphans in the country's hospitals have motivated the government to explore the promotion of breastmilk feeding utilizing donor breastmilk banks [21]. Prevalence of low birth weight is currently estimated at $10 \%$, while cases of preterm babies are common in tertiary hospitals although scientifically reported national data are scarce [16]. Evidence also indicates that maternal deaths are high during the peak childbearing age, suggesting high numbers of orphans under 2 months of age [16]. In line with the country's policy to ensure all children receive breastmilk, DHM banks provide an opportunity to ensure universal access to breastmilk for all children aged 0-24 months. Clearer understanding of the perceptions of health workers and policy makers could facilitate more effective interventions.

Breastmilk protects preterm babies against necrotizing enterocolitis, sepsis, improves neurodevelopmental outcomes, tolerance of feedings and shortens the length of stay in neonatal intensive care units (NICU) providing direct cost savings [3, 22-27]. DHM is associated with increased EBF rates, and increased awareness of families and NICU staff on the value of breastfeeding. Further, DHM banking provides an opportunity for lactation support to mothers as well as protection of breastfeeding through an integrated framework of newborn care [28-30].

Developing countries have demonstrated capacity to manage breastmilk banks successfully. Brazil has the largest network of DHM banks in the world with over 219 banks. Other African countries such as South Africa and Kenya have established a network of DHM banks despite facing epidemics of infectious diseases such as HIV, TB and hepatitis $[5,6,31-34]$. The role of health workers has been crucial in the success of DHM banks. However, health workers' attitudes, fragmented systems, lack of government policy support, maternal and community negative perceptions and detrimental cultural practices often prevent success of DHM banks [29, 33, 35]. Health workers play a key role in motivating and influencing mothers to donate breastmilk. In the Brazilian experience, mothers obtained information about a DHM bank during their stay at a hospital and were influenced to donate breastmilk by a health worker [5]. This strategy indicated that success or failure of DHM banks is hinged on health workers.

In Zimbabwe, limited data exists on how health workers perceive the practice of DHM banks. This study was designed to assess the acceptability and perceptions of DHM banks among health workers in a low-income urban setting in the context of high HIV prevalence.

\section{Methods \\ Study setting}

The study was conducted at Parirenyatwa Group of Hospitals, Harare Central Hospital and Mpilo Central Hospital in the two major cities of Zimbabwe between October 2017 and October 2018. These are the major referral hospitals in the country. These hospitals are potential pilot locations for establishing breastmilk banks in the country. Harare is the capital city of Zimbabwe and has a total population of 2,123,132 (according to the 2012 Census) with a proportion of women of child bearing age of $58.6 \%$, and children below the age of five at $14.1 \%$. Bulawayo is the second largest city in the country [36].

\section{Study design}

A cross-sectional survey was conducted among health workers at three tertiary health institutions. A mixed methods approach was applied using both quantitative and qualitative methods. Key informant interviews were conducted with hospital management to explore the readiness of Zimbabwe tertiary hospitals to implement donor breastmilk banks, in addition to opinion leaders involved in health and nutrition policies.

\section{Study population, sampling and eligibility criteria}

The three referral hospitals were purposively selected, and a systematic random sampling method used to select health workers to be interviewed from maternal, medical and paediatric wards as well as nutrition departments. Sample size was based on Naing's formula using $\alpha=0.05$ and $95 \%$ significance level and 50\% estimated prevalence of knowledge, attitude and perceptions [37]. A sample size of 384 health workers from the three hospitals was found to be adequate. Fifteen key informants were purposively selected so as to include all relevant 
administrative departments at each health institution and national management in the Ministry responsible for Health and Child Care.

Health workers working at Parirenyatwa Group of Hospitals, Harare Central Hospital and Mpilo Central Hospital at the time of data collection were eligible to participate in the study. Health workers were grouped based on their professional roles; doctors, nurses, midwives, nutrition and general staff. Management staff of the tertiary hospitals including head of departments from both clinical and administrative departments were included in the study as key informants. Opinion leaders in the health and nutrition sector including key development partners in these sectors were included as key informants as well.

\section{Interviewing and data collection}

Health workers were interviewed using a structured, self-administered questionnaire. The questionnaire was pretested among health workers at one polyclinic in Harare. Key informant interviews (KIIs) were conducted with hospital management, the Ministry of Health and Child Care's opinion leaders. Hospital managers were selected from the same tertiary hospitals as health workers and interviewed separately. The Hospital Managers interviewed included two Hospital Chief Executive Officers, three Principal Nursing Officers, two Clinical
Directors, two Dietetics and Nutrition Department Managers and one Operations Director. The Opinion Leaders interviewed included two Family Health and Nutrition Directors, two Nutrition Technical Specialists and the President of the Zimbabwe Midwives Association (see Fig. 1).

\section{Statistics and data analysis}

The data were analyzed to determine suitability, reliability, adequacy and accuracy using STATA V13 software package (StataCorp, 2013) [38]. Unless otherwise stated, all analyses of the quantitative data were presented as mean \pm SD and the level of significance was set at $P<$ 0.05 . Chi-squared testing was used to test for significant difference in characteristics related to knowledge and acceptance of BM banks. Binary logistic regression analysis was employed to test for association between health workers' personal and professional characteristics with their acceptance of BM banks. Qualitative data were analyzed using content analysis of themes employing Microsoft Excel. All interviews were transcribed, and a cross-case analysis was used to identify themes from the combined responses of all key informants.

The data were initially examined by the themes and topics employed in the interview guide to establish participants' knowledge and perceptions on establishing breastmilk banks in the country. An inductive analysis

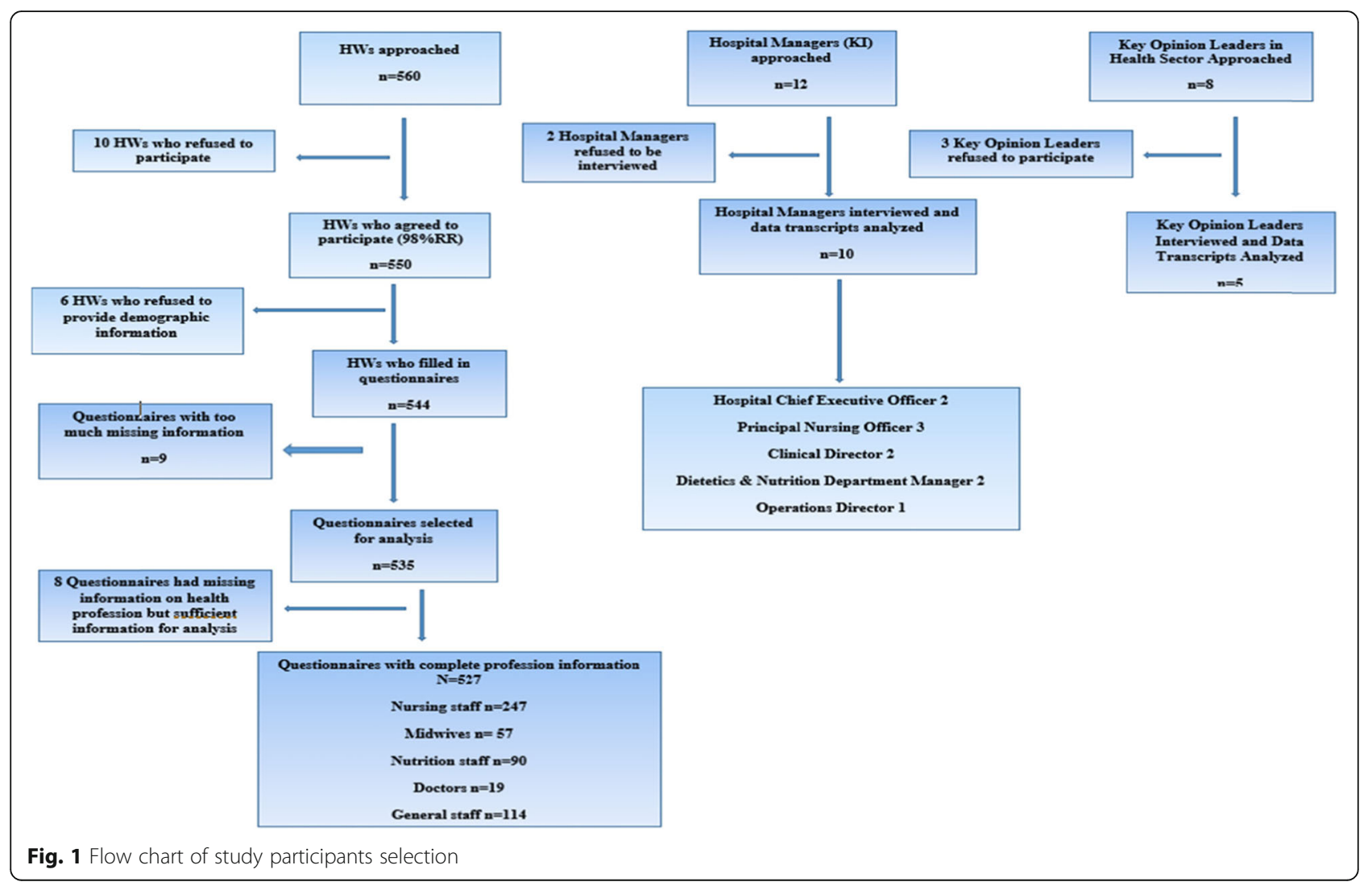


was then used to identify further themes, sub-themes and patterns in the data. The following steps were employed for the qualitative data analysis. 1) Reading and re-reading the responses to become familiar with the text and begin developing codes. 2) Coding the data to identify themes and sub-themes. 3) Displaying details of categories and themes (e.g. identifying variations within each theme, noting differences between individuals and among sub-groups, and exploring nuances in the text). 4) Reducing the data to essential points, and 5) developing an overall interpretation based on this process [39]. Key themes were generated from full transcripts of interviews from key informants and opinion leaders. This was conducted by employing content analysis generating themes and sub-themes. Data triangulation was achieved using qualitative data from KIIs to corroborate the information reported by health workers from the structured questionnaires. The primary data analysis was conducted by DTC and FM. To avoid bias and ensure consensus, data checking and review of the content analysis was conducted by a senior author (TM).

\section{Results}

The survey results were presented and compared with verbal quotes from the key informant interviews. Of the 535 health workers who participated in the study $72 \%$ were female, $47 \%$ were nurses, $66 \%$ were married and $5 \%$ had previously worked in a setting with a breastmilk bank (Table 1).

\section{Knowledge on human milk banking and infant feeding}

More than half the health workers (58\%) were aware of breastmilk banks, and more than two-thirds (71\%) knew of the human milk banking practice. Personal knowledge, the workplace and internet were reported as the major source of information regarding breastmilk banks by health workers (Table 2 ).

Only 35\% of respondents knew that donor breastmilk had to be processed to make it safe for consumption by recipient babies. Knowledge on breastmilk banks and processing of DHM was significantly associated with health workers' profession (Table 3). The practice of wet-nursing was also well-understood among the interviewed health workers. More than two-thirds (67\%) of respondents had an adequate knowledge about wet nursing, and knowledge on wet nursing was associated with having a child ( $p=0.023)$.

All but one key informant had previously heard about human milk banks. Nursing managers and dieticians gave the correct scientific definition of breastmilk banks while other hospital managers, although correct, demonstrated layman's ideas. In cases where knowledge on human milk banking was poor, donor breastmilk banks were confused with breastmilk expressed by mothers to
Table 1 Socio-demographic characteristics of Health Workers in Zimbabwean Tertiary Hospitals $(n=535)$

\begin{tabular}{|c|c|c|}
\hline Characteristics & $\mathrm{n}$ & $\%$ \\
\hline \multicolumn{3}{|l|}{ Tertiary Hospitals $(n=535)$} \\
\hline Parirenyatwa Hospital & 237 & 44 \\
\hline Harare Hospital & 220 & 41 \\
\hline Mpilo Hospital & 78 & 15 \\
\hline \multicolumn{3}{|l|}{ Gender of Respondents $(n=535)$} \\
\hline Male & 150 & 28 \\
\hline Female & 385 & 71 \\
\hline \multicolumn{3}{|l|}{ Profession of respondents $(n=527)$} \\
\hline Nursing & 247 & 47 \\
\hline Midwife & 57 & 11 \\
\hline Nutrition & 90 & 17 \\
\hline Doctor & 19 & 4 \\
\hline General staff & 114 & 22 \\
\hline \multicolumn{3}{|l|}{ Marital status of respondents $(n=528)$} \\
\hline Single & 146 & 28 \\
\hline Married & 348 & 66 \\
\hline Divorced & 9 & 2 \\
\hline Widow & 25 & 5 \\
\hline Respondents with children $(n=535)$ & 426 & 80 \\
\hline \multicolumn{3}{|l|}{ Religion $(n=535)$} \\
\hline None & 7 & 1.31 \\
\hline Christianity & 517 & 96.64 \\
\hline Muslim & 3 & 0.56 \\
\hline African traditional religion & 3 & 0.56 \\
\hline Apostolic sector & 5 & 0.93 \\
\hline
\end{tabular}

*Where $n<535$ represents participants with missing data on those variables

Table 2 Awareness and common sources of information regarding breastmilk banks

\begin{tabular}{lcc}
\hline & $\mathrm{n}$ & $\%$ \\
\hline Awareness of BM Banks $(n=535)$ & 306 & 58 \\
Correct definition of breastmilk bank $(n=525)$ & 371 & 71 \\
Health previously exposed to donor breastmilk banks $(n=535)$ & 27 & 5 \\
Common sources of information on breastmilk milk donation $(n=365)$ & 38 & 10 \\
Formal education & 56 & 15 \\
Internet & 11 & 3 \\
Media & 48 & 13 \\
Other people & 93 & 25 \\
Workplace & 119 & 33 \\
Personal knowledge & 33 \\
\hline
\end{tabular}

*Where $n<535$ represents participants with missing data on those variables 
Table 3 Knowledge of breastmilk banks and infant feeding among health workers in Zimbabwean tertiary hospitals $(n=535)$

\begin{tabular}{|c|c|c|c|c|c|c|}
\hline \multirow[b]{2}{*}{ Profession } & \multicolumn{2}{|c|}{$\begin{array}{l}\text { HEALTH WORKERS } \\
\text { with adequate knowledge on } \\
\text { wet nursing }\end{array}$} & \multicolumn{2}{|c|}{$\begin{array}{l}\text { HEALTH WORKERS } \\
\text { who knew } \\
\text { the concept of breastmilk banks }\end{array}$} & \multicolumn{2}{|c|}{$\begin{array}{l}\text { HEALTH WORKERS } \\
\text { who knew about processing of } \\
\text { donor breastmilk }\end{array}$} \\
\hline & $n$ & $\%$ & $n$ & $\%$ & $n$ & $\%$ \\
\hline Nursing staff & 177 & 72 & 182 & 76 & 79 & 32 \\
\hline Midwife & 50 & 88 & 43 & 78 & 26 & 46 \\
\hline Nutrition staff & 72 & 80 & 52 & 58 & 30 & 34 \\
\hline Doctors & 9 & 47 & 15 & 83 & 14 & 74 \\
\hline General staff & 44 & 39 & 71 & 66 & 34 & 30 \\
\hline Total & 352 & 67 & 363 & 71 & 183 & 35 \\
\hline$p$ value & \multicolumn{2}{|l|}{$P<0.001$} & \multicolumn{2}{|c|}{$P=0.005$} & \multicolumn{2}{|c|}{$P=0.015$} \\
\hline
\end{tabular}

feed their babies when they are away. One nursing manager articulated a breastmilk bank as:

"A recognized service which is responsible for collecting, screening, processing and dispensing of human milk through prescription. The breast milk is donated by nursing mothers who are not the biological mother of the recipient infant." Nursing manager.

\section{Acceptance of donor human milk banking}

The concept of DHM banking was fairly acceptable to health workers. About one-third (31\%) reported that they would accept donor breastmilk to feed their own children, $47 \%$ would agree to donate or allow their partners to donate breastmilk through DHM banks, and 56\% would encourage their clients to donate breastmilk to a DHM bank. Acceptance of donor human milk was associated with the participants' health profession $(p=0.001)$ and level of knowledge on breastmilk banks $(p=0.009)$, but not associated with religion $(p=0.498)$, marital status $(p=0.714)$ or gender $(p=0.000)$. (Table 4$)$.

Doctors demonstrated high acceptance of donor breastmilk banking (63\%) compared to other professions $(p=0.001)$. Most health workers in the nutrition (59\%), midwifery (58\%), and medical fields (79\%) reported a willingness to donate human breastmilk compared to health workers in the nursing (39\%) and general fields (44\%). Doctors (78\%), midwives (62\%) and nutrition
(68\%) professionals were more likely to encourage mothers to use donor human milk. Health workers with knowledge on the concept of human milk banks were more receptive to donate $(p=0.025)$, accept $(0.009)$ and encourage (0.001) mothers to use donor breastmilk. More than half $(56 \%)$ of the health workers reported they would encourage their clients to donate breastmilk to a DHM bank, although only $47 \%$ were willing to donate to a DHM bank themselves. Only $31 \%$ were willing to accept DHM for their own children.

All hospital managers (100\%) accepted the concept of DHM banking. They reported that it was necessary to establish breastmilk banks in referral hospitals of Zimbabwe.

"We need breastmilk banks to cater for babies whose mothers die within the first to second year of life and the remaining guardian cannot afford formula milk, and also for babies whose mothers cannot feed for medical reasons or are unable to produce adequate milk supplies" Nursing manager.

Hospital managers also reported that donor breastmilk should be provided and made available as medical therapy, not for convenience.

"Breastmilk banks are required in order to give newborn infants the best start in life and to achieve high

Table 4 Acceptance of donor human milk banking among health workers in Zimbabwean Tertiary Hospitals $(n=527)$

\begin{tabular}{|c|c|c|c|c|c|c|}
\hline \multirow[b]{2}{*}{ Profession } & \multicolumn{2}{|c|}{$\begin{array}{l}\text { HEALTH WORKERS willing to donate to a } \\
\text { BM Bank }\end{array}$} & \multicolumn{2}{|c|}{$\begin{array}{l}\text { HEALTH WORKERS willing to } \\
\text { accept DHM }\end{array}$} & \multicolumn{2}{|c|}{$\begin{array}{l}\text { HEALTH WORKERS willing to encourage mothers } \\
\text { to use DHM }\end{array}$} \\
\hline & $\mathrm{n}$ & $\%$ & $n$ & $\%$ & $\mathrm{n}$ & $\%$ \\
\hline Nursing staff & 96 & 39 & 59 & 24 & 119 & 48 \\
\hline Midwives & 33 & 58 & 18 & 31 & 35 & 62 \\
\hline Nutrition staff & 53 & 59 & 24 & 27 & 61 & 68 \\
\hline Doctors & 13 & 70 & 12 & 63 & 15 & 78 \\
\hline General staff & 50 & 44 & 46 & 40 & 63 & 55 \\
\hline All Health Workers & 248 & 47 & 163 & 31 & 295 & 56 \\
\hline
\end{tabular}


breastfeeding rates. We should have a system that ensures availability of breastmilk as a form of medical therapy and not a convenience. We should treat breastmilk as a medicine which all children have the right to receive from birth" Dietician.

\section{Reasons for health worker willingness or reluctance to donate or receive breastmilk from a breastmilk bank}

Among the health workers who reported that they would donate breastmilk to a donor human milk bank, a common reason was to help other babies in need of breastmilk (80\%). Some (41\%) would not donate breastmilk due to fear of transmitting diseases to other children especially HIV. Table 5 shows common reasons why health workers would be willing to donate breastmilk to a human milk bank. Among health workers who would accept donor breastmilk, the majority (88\%) would accept DHM because they regarded breastmilk as important for health and growth of children. Among those who rejected DHM, most health workers (61\%) did so due to fear of transmission of diseases such as HIV (Table 6).

\section{Perceptions on donor human milk banking}

From the survey, more than half the health workers (57\%) reported that breastmilk banks were important in Zimbabwe and half (50\%) reported that the country could afford to introduce donor human milk banks (Table 7). There was general agreement that breastmilk banks were beneficial and most health workers (66\%) reported that DHM banks reduced mortality and morbidity among preterm and orphan babies in hospitals (Table 7).

Generally, health workers showed positive perceptions towards breastmilk banks, even though less than half (44\%) indicated that DHM banks were safe. However, from interviews, hospital managers and dieticians had confidence in the safety of donor breastmilk.
Table 6 Factors that influence health workers' decision to receive DHM from a breastmilk bank $(n=518)$

\begin{tabular}{lll}
\hline Reason HEALTH WORKERS would accept to receive DHM & $\mathrm{n}$ & $\%$ \\
\hline Breastmilk is important to children & 146 & 88 \\
The practice is safe & 19 & 11 \\
I would accept after receiving more information & 1 & 1 \\
Reasons HEALTH WORKERS would not accept to receive donor human milk \\
Fear of diseases & 215 & 61 \\
Unacceptable & 80 & 23 \\
Inadequate knowledge on DHM banks & 30 & 9 \\
Prefer formula milk & 18 & 5 \\
DHM not safe & 9 & 3 \\
\hline
\end{tabular}

"Of course, donor human milk is safe ...because it will be treated, and all possible harmful agents removed just like cow's milk is processed when formula is being made" Dietitian.

There was agreement among hospital managers that breastmilk donors were adequately screened, and donor human milk was treated and rendered safe to feed to infants. Appropriate storage conditions and measurements were reported as important factors to ensure the safety of donor human milk.

"It can only be safe if there is proper screening for infections such as HIV and if proper storage is ensured" Clinical Director.

\section{Perceptions of health workers on donor human milk banking in a high HIV setting}

Table 7 shows health workers' views on elimination of HIV during donor human milk processing. Only 35\% of health workers reported that HIV could be eliminated during treatment and processing of DHM. More than half of the doctors (53\%) were aware that HIV and other diseases were eliminated during processing of DHM.

Table 5 Factors that influence health workers' willingness to donate breastmilk to a donor human milk bank $(n=535)$

\begin{tabular}{lll}
\hline Reasons HEALTH WORKERS would agree to donate breastmilk to a bank & $\mathrm{n}$ & \% \\
\hline Help other babies & 39 & 80 \\
Breastmilk is important & 9 & 16 \\
I have adequate knowledge on DHM banks & 4 \\
Reasons HEALTH WORKERS would not agree to donate breastmilk to a bank & 121 & 41 \\
Fear of Diseases & 87 & 30 \\
Unacceptable & 63 & 21 \\
I have Inadequate knowledge & 8 & 2 \\
The practice is unethical & 10 & 1 \\
Decision lies with my partner & 5 & 1 \\
The practice is not safe & & 41 \\
\hline
\end{tabular}


Table 7 Perceptions on donor human milk banking among health workers from tertiary Hospitals in Zimbabwe

\begin{tabular}{lll}
\hline Health Workers who responded yes to the statement; & $n$ & n \\
\hline Reduce morbidity and mortality of pre-terms and orphans in hospitals & 349 \\
BM banks are important in our hospitals & 304 & 66 \\
BM banks are affordable to set up in Zimbabwe & 266 \\
Breast milk donors should receive financial compensation when they donate breast milk & 254 \\
BM banks have safe breastmilk & 230 \\
Breast milk donors should receive non-financial compensation when they donate breast milk & 223 \\
BM banks are effective in removing all risk of disease or infection including HIV & 181 \\
\hline
\end{tabular}

Perception on elimination of HIV in DHM during processing was associated with health profession $(p=0.036)$ but not associated with the level of knowledge of breastmilk banks $(p=0.167)$. Most respondents from other professions among health workers other than doctors were not aware that treatment of donor breastmilk eliminated HIV (Fig. 2).

Most of the hospital managers reported that donor breastmilk could be made safe and free from HIV if donors were screened and donor breastmilk underwent proper treatment processes and storage. Other hospitals managers perceived donor human milk banking as a cost-effective strategy and a more beneficial means to feed infants born to HIV-infected mothers.

"Donor breastmilk is actually a cost-effective means of ensuring children born to HIV positive mothers receive breastmilk. As opposed to sourcing infant formula as an alternative feed which is costly and requires certain conditions for preparation and storage, increasing risk of contamination and malnutrition" Dietetics and nutrition department manager.

There was consensus among hospital managers that Zimbabwe was in a position to treat and process donor human milk in the referral hospitals if resources were provided and priorities set by the government and the private sector.

One clinical director and a nursing manager reported:

"It is possible to safely treat and process donor breastmilk even in this setting where HIV rates are high if resources are available, both human and material and if priorities are made up correctly".

\section{Factors influencing acceptance of donor human milk banking among health workers}

Health workers' willingness to encourage mothers to use donor human milk was positively associated with increased knowledge on DHM banking $(p=0.002)$ and prior exposure to a worksite with a DHM bank $(P=$ 0.015). Health workers with knowledge on DHM banking and those who had previously worked in a setting where a breastmilk bank was present were $52 \%$ (OR 1.52 CI 1.34; 1.78. $p=0.002$ ) and 36\% (OR 1.36 CI 1.16; 2.82 . $p=0.015)$ more likely to encourage mothers to use donor breastmilk respectively. Religion $(p=0.624)$ and awareness of DHM banking $(p=0.52)$ did not influence health workers' acceptance to DHM. 
Readiness and commitment of tertiary hospitals to implement donor human milk banking

Referral hospital management staff for Parirenyatwa and Harare Central Hospitals were committed and eager to have breastmilk banks established to improve breastfeeding rates and provide a chance of feeding breastmilk to infants unable to be breastfed for medical or other reasons. Hospital managers reported that the commitment to establishing breastmilk banks was high.

"Challenges like unavailability of human and material resources, equipment, limited or improper infrastructure need to be addressed to make it possible" Clinical director and nursing manager.

One clinical director highlighted that hospital management were aware of the need to establish breastmilk banks as the issue had been raised during planning meetings the year prior to the current study. Other middle-level managers reported that although commitment towards breastfeeding initiatives among hospital decision makers was often reported as high, actual efforts to provide resources was very low. This comment reflected the limited support given to policies that promoted breastfeeding such as the BFHI. Another key informant at middle management level reported that referral hospitals' commitment to breastfeeding or even establishing a breastmilk bank seemed low because of the lack of resources and lack of knowledge on the importance of breastfeeding among health workers.

"A lot of education is needed for staff members before this can be done. Too many misconceptions about the milk banks" Dietician.

Respondents felt that the government and nutrition community in the country needed to act swiftly to move forward the agenda on donor human milk banking. One clinical director stated that, "the issue of breastmilk banks is now long overdue for a country and a city like Harare with so many infants and neonates who may benefit from it."

\section{Discussion}

This study showed that health workers were more receptive to donating DHM and more likely to encourage others to use DHM banks than receiving DHM themselves. Only about one third (31\%) of health workers reported they would accept donor breastmilk to feed their own children, while $47 \%$ would agree to donate or allow their partners to donate breastmilk to DHM banks. Fifty-six per cent indicated they would encourage their clients to use DHM banks. Amongst the professions interviewed, doctors demonstrated the highest acceptance of DHM banks. Knowledge on DHM banks and prior work at a health facility with a DHM bank was shown to positively influence acceptance of DHM banking. Helping babies in need of breastmilk was identified as the major reason to donate breastmilk, while the fear of HIV transmission was the major barrier to DHM banking acceptance.

Most health workers were either aware of, or had adequate knowledge of DHM banking, based on their personal knowledge and work experience. Professional knowledge and experience with blood banks may have contributed to their knowledge on DHM banks. This finding indicated limited knowledge on infant feeding options among tertiary-level health workers which is detrimental to national progress in child health. In a country where breastfeeding is highly regarded and the BFHI program is being advanced, there was need for extensive investment on infant feeding education among health professionals [40]. Considering most mothers relied on health workers for information on DHM and breastmilk feeding, it was important for health workers to have adequate knowledge on the subject $[6,32,34]$. Considering many working mothers in urban resourcelimited settings needed strong encouragement to use expressed breast milk, such an investment in health professional education should be essential [4, 41, 42]. Education on Infant and Young Child Feeding, and components on use of DHM for medical purposes could be incorporated during in-service training for health professionals.

Findings from interviews with hospital management and key opinion leaders in the health sector demonstrated high acceptance of DHM banks. This was important considering most resource-limited countries were considering health interventions that save lives and reduce health costs, both of which are commonly associated with DHM banks. Brazil's comprehensive DHM bank approach saves the country about US\$540 million annually in medical costs $[4,43,44]$. Among the main referral hospital staff in Zimbabwe, acceptance of DHM banking was high among doctors and fair among other health professionals. Doctors also demonstrated increased knowledge of DHM and adequate knowledge on processing of DHM compared to other health professionals. Health workers with increased knowledge on the concept of DHM banking were more receptive to DHM banks and indicated the need for a greater level of knowledge as critical to motivate acceptance of DHM banking [32].

The main barrier to DHM banking was the fear of infectious diseases. This finding was consistent with studies elsewhere where safety of DHM was a major obstacle to DHM banking $[6,45]$. A few health workers believed that donor breastmilk was safe and its treatment could 
eliminate disease pathogens including HIV. Most health workers were more comfortable with encouraging clients to use DHM banks or donating breastmilk themselves than accepting DHM for their own children. This finding reflected a fear of disease and lack of familiarity with processes involved in DHM treatment which could be addressed through health education programs.

A few health workers reported that the practice of DHM banking was unacceptable. Such beliefs could potentially affect general acceptance of DHM banks by communities. To ensure success of DHM banks in Zimbabwe, education on the principles of the banks is a pre-requisite to ensure health workers' trust in the practice. Opinions of mothers and caregivers on DHM are mainly influenced by health workers as indicated elsewhere $[5,34,42,46]$. Hence getting health workers on board is the entry point for DHM banks in settings where HIV prevalence is high and strong cultural perceptions on infant-feeding exist. Lack of familiarity with DHM banking was a major obstacle to acceptance of DHM by mothers in a similar setting in South Africa [6].

Even with some misconceptions on safety, the fact that most health workers were keen to encourage mothers to use DHM reflected the potential success of the DHM bank initiative. This encouragement was despite the fact that more than half of respondents believed that DHM was not safe and could not be processed to eliminate HIV and other pathogens (Table 7). Doctors and midwives were more receptive to DHM banking possibly due to extended period of education and experience in the clinical setting [47, 48]. It requires seven to nine years to qualify as a medical doctor or midwife in Zimbabwe, during which time exposure to infants with special needs in NICUs is high. Contrary to prior assumptions, staff in the nutrition field were not highly knowledgeable and accepting of DHM banking, possibly because other nutrition support staff such as hospital food service supervisors were less exposed to breastfeeding and NICUs.

Fear of HIV is potentially the main barrier to accessing DHM banks, and this was anticipated as Zimbabwe is a high HIV setting [3, 6, 31]. Information from a clinical director at one of the tertiary institutions revealed that the country had formerly established DHM banks in the 1990s which were closed during the initial stages of the HIV epidemic [16]. Since then, technological advances and the pasteurization of DHM can eliminate HIV in EBM. Consequently, hospital managers and health sector key opinion leaders did not view HIV as an obstacle to DHM banks as it can be eliminated during treatment and donors are rigorously screened [49-51]. The current requirement is government's commitment and investment in DHM treatment and processing to ensure success of the initiative.
Comments by managers that commitment to investment in breastfeeding by the government was insufficient and that there was a lack of knowledge on infant feeding among health workers highlights the importance of education around protecting, promoting and supporting breastfeeding. An integrated DHM bank model with newborn care services could improve the country's breastfeeding rates, reduce the healthcare cost of managing preterm babies, and improve child health care [29, 52]. Hygiene and handling of DHM by caregivers needs critical attention considering that water and sanitation infrastructure have deteriorated in such settings [53]. Other authors have argued that DHM could be expensive when compared with formula milk [52], and that feeding DHM collected from full term mothers late in lactation could result in milk composition that is unsuited to the needs of preterm infants and requires additional human milk fortifiers [54]. Despite such challenges, DHM particularly exclusive-human milk diets, offer infants better protection from the risk of necrotizing enterocolitis, sepsis and feeding intolerances [13, 23, 26].

Participants recruited for this study were limited to health workers in tertiary hospitals and potential sites of DHM banks. Consequently, the sample was not representative of health workers in the country. Other groups with direct influence on mothers' infant feeding decisions such as husbands and mothers-in-law were not included in the study.

\section{Conclusions}

Donor human milk banks were acceptable to health workers, and the level of acceptance was higher among doctors, health workers with adequate knowledge of DHM banking and health sector policy reformers. While a willingness to establish DHM banks in major referral hospitals was high, limited finances and facilities and a fear of HIV infection were potential barriers. Consequently, financial commitment from authorities, and education among health workers on the safety of DHM is crucial to the success of DHM banking in HIV endemic areas.

\section{Abbreviations}

BFHI: Baby Friendly Hospital Initiative; BM: Breastmilk; DHM: Donor human milk; EBF: Exclusive Breast Feeding; HIV: Human Immune Deficiency Virus; NICU: Neonatal Intensive Care Units; WHO: World Health Organisation

\section{Acknowledgements}

We would like to express our deepest gratitude to the staff at Parirenyatwa Group of Hospitals, Harare and Mpilo Central Hospitals. Special mention is also accorded to Mrs. E Katuruza, Ms. K Chinduli and Miss R Masendu for assisting with data collection. DTC received research training and mentorship through a Fogarty International Center funded program, Award Number D43TW007991 and CCM received support as a mentor. 


\section{Ethics and consent to participate}

Ethics approval to conduct the study was obtained from the Harare Central Hospital Ethics Committee (HCHEC 150218/14) and the Medical Research Council in Zimbabwe (MRCZ/B/1442). Written consent was established from study participants.

\section{Authors' contributions}

DTC conceived the idea presented, designed the study, carried out data collection, analysis and took lead in writing the manuscript. FM and BS contributed in the design of the study and finalisation of the study proposal, data collection and data analysis. SM and RD contributed in designing the study and conducted part of the data collection. TM provided substantive input in the review of the study design, data analysis and writing of the manuscript. CCM critically reviewed the conceptualised idea, contributed to study design and provided guidance to shape the research. All authors provided critical feedback on the analysis and writing of the manuscript, discussed the results and provided comments. The author(s) read and approved the final manuscript.

\section{Funding}

The authors did not receive any external funding to conduct this study.

\section{Availability of data and materials}

The datasets used and analysed during the current study are available from the corresponding author upon reasonable request.

\section{Consent for publication}

Not applicable.

\section{Competing interests}

The authors declare that they have no competing interests.

\section{Author details}

${ }^{1}$ School of Pharmacy, College of Health Sciences, University of Zimbabwe, Harare, Zimbabwe. ${ }^{2}$ Nutri@ctive Zimbabwe, 96 Golden Stairs Rd, Mt Pleasant, Harare, Zimbabwe. ${ }^{3}$ Institute of Food, Nutrition and Family Sciences, Mt Pleasant, Harare, Zimbabwe. ${ }^{4}$ Ministry of Health and Child Care, Causeway, Harare, Zimbabwe. ${ }^{5}$ UNICEF, 6 Fairbridge Avenue, Belgravia, Harare, Zimbabwe.

\section{Received: 28 March 2019 Accepted: 28 April 2020}

\section{Published online: 11 May 2020}

\section{References}

1. World Health Organization. Guidelines on optimal feeding of low birthweight infants in low- and middle-income countries. Geneva: WHO Press; 2011.

2. American Academy of Pediatrics Committee on Nutrition. Pediatric nutrition handbook. Elk Grove Village (IL): American Academy of Pediatrics; 2014.

3. Arslanoglu S, Corpeleijn W, Moro G, Braegger C, Campoy C, Colomb V, et al. Donor human milk for preterm infants: current evidence and research directions. J Pediatr Gastroenterol Nutr. 2013;57(4):535-42.

4. World Health Organization. UNICEF: Every Newborn: An Action Plan to end Preventable Deaths. Geneva: World Health Organization; 2014.

5. Pimenteira Thomaz AC, Maia Loureiro LV, da Silva OT, Furtado Montenegro NC. Dantas Almeida junior E, Fernando Rodrigues Soriano C, et al: the human milk donation experience: motives, influencing factors, and regular donation. J Hum Lact. 2008;24(1):69-76.

6. Coutsoudis I, Petrites A, Coutsoudis A. Acceptability of donated breast milk in a resource limited south African setting. Int Breastfeed J. 2011;6:3.

7. Horta BL, Loret de Mola C, Victora CG. Breastfeeding and intelligence: a systematic review and meta-analysis. Acta Paediatr. 2015;104(S467):14-9.

8. Rollins NC, Bhandari N, Hajeebhoy N, Horton S, Lutter CK, Martines JC, et al. Why invest, and what it will take to improve breastfeeding practices? Lancet. 2016;387(10017):491-504.

9. Walters D, Horton S, Siregar AY, Pitriyan P, Hajeebhoy N, Mathisen R, Phan $L T$, Rudert C. The cost of not breastfeeding in Southeast Asia. Health Policy Plan. 2016;31(8):1107-16

10. World Health Organization. Technical updates of the guidelines on the integrated Management of Childhood IIIness (IMCI). Geneve, Switzerland: World Health Organization; 2005.
11. Smith JP. "lost milk?": counting the economic value of breast milk in gross domestic product. J Hum Lact. 2013;29(4):537-46.

12. Stevens EE, Patrick TE, Pickler R. A history of infant feeding. J Perinatal Education. 2009;18(2):32-9.

13. World Health Organization. UNICEF: guideline: updates on HIV and infant feeding: the duration of breastfeeding, and support from health services to improve feeding practices among mothers living with HIV. Geneva: World Health Organization; 2016.

14. Alvarez-Uria G, Midde M, Pakam R, Bachu L, Naik PK. Effect of formula feeding and breastfeeding on child growth, infant mortality, and HIV transmission in children born to HIV-infected pregnant women who received triple antiretroviral therapy in a resource-limited setting: data from an HIV cohort study in India. Int Scholar Res Notes Pediatrics. 2012.

15. World Health Organization. Acceptable medical reasons for use of breastmilk substitutes. Geneva, Switzerland: World Health Organization; 2009.

16. Zimbabwe National Statistics Agency. Zimbabwe demographic and health survey 2015: final report. In. Rockville, Maryland: Zimbabwe National Statistics Agency/ICF International; 2016.

17. Food and Nutrition Council. Zimbabwe National Nutrition Survey 2018: Final report in. Harare: Food and Nutrition Council; 2018.

18. Ministry of Health and Child Welfare. Infant and Young Child Feeding Policy number: MOHCW/IYCF/01/2013: Draft. Harare: Ministry of Health and Child Welfare; 2013.

19. World Health Organization. Global strategy for infant and young child feeding. Geneva: World Health Organization; 2003.

20. National Medicines and Therapeutics Policy Advisory. Guidelines for Antiretroviral Therapy for the Prevention and Treatment of HIV in Zimbabwe. In. Edited by AIDS and TB Directorate. Causeway, Harare: Ministry of Health and Child Care; 2016.

21. Ministry of Health and Child Welfare. Baby-friendly hospital initiative training reports: Parirenyatwa hospital trainings in. Harare: Ministry of Health and Child Welfare/UNICEF; 2014.

22. Mcguire W, Anthony MY. Donor human milk versus formula for preventing necrotising entrocolitis in preterm infants: systematic review. Arch Dis Child Fetal Neonatal Ed. 2003;88:F11-4.

23. Ronnestad A, Abrahamsen TG, Medbo S, Reigstad H, Lossius K. Kaaresen PI, et at: late-onset septicemia in a Norwegian national cohort of extremely premature infants receiving very early full human milk feeding. Pediatrics. 2005;115(3):e269-76

24. Mackenzie C, Javanparast S, Newman L. Mothers' knowledge of and attitudes toward human milk banking in South Australia: a qualitative study. J Hum Lact. 2013;29(2):222-9.

25. Quigley M, Embleton ND, McGuire W. Formula versus donor breast milk for feeding preterm or low birth weight infants. Cochrane Database Syst Rev. 2018;6:CD002971

26. Schanler RJ, Lau C, Hurst NM, Smith EO. Randomized trial of donor human milk versus preterm formula as substitutes for mothers' own milk in the feeding of extremely premature infants. Pediatrics. 2005;116(2):400-6.

27. Commonwealth of Australia. Donor human milk banking in Australia- Issues and background paper. Australia: Australian Government Department of Health; 2014.

28. Arslanoglu S, Moro Guido E, Bellù R, Turoli D, De Nisi G, Tonetto P, et al. Presence of human milk bank is associated with elevated rate of exclusive breastfeeding in VLBW infants. J Perinat Med. 2012;41(2):1-3.

29. DeMarchis A, Israel-Ballard K, Mansen KA, Engmann C. Establishing an integrated human milk banking approach to strengthen newborn care. J Perinatol. 2017:37(5):469-74.

30. Parker MG, Burnham L, Mao W, Philipp BL, Merewood A. Implementation of a donor milk program is associated with greater consumption of mothers' own milk among VLBW infants in a US, level 3 NICU. J Hum Lact. 2016;32(2): 221-8.

31. Ighogboja IS, Olarewaju RS, Odumodu CU, Okuonghae HO. Mothers' attitudes towards donated breastmilk in Jos, Nigeria. J Human Lactation. 1995:11(2):93-6.

32. Iloh KK, Osuorah CD, Ndu IK, Asinobi IN, Obumneme-Anyim IN, Ezeudu CE, et al. Perception of donor breast milk and determinants of its acceptability among mothers in a developing community: a cross-sectional multi-center study in south-East Nigeria. Int Breastfeed J. 2018;13:47.

33. PATH. Strengthening human milk banking: a global implementation framework. Version 1 Bill \& Melinda Gates Foundation grand challenges initiative. In. Seattle, WA: PATH; 2013. 
34. McCloskey RJ, Karandikar S. A liberation health approach to examining challenges and facilitators of peer-to-peer human milk sharing. J Hum Lact. 2018;34(3):438-47.

35. Brownell EA, Lussier MM, Herson VC, Hagadorn Jl, Marinelli KA. Donor human milk bank data collection in North America: an assessment of current status and future needs. J Hum Lact. 2014;30(1):47-53.

36. Zimbabwe National Statistics Agency. Zimbabwe Population Census Results. In. Harare, Zimbabwe; 2012. p. 1.

37. Naing NN. Determination of sample size. Malaysian J Med Sci. 2003;10(2): 84-6.

38. StataCorp. Stata: Release 13. Statistical software. College Station, TX: StataCorp LP; 2013.

39. Ulin PR, Robinson ET, Tolley EE. Qualitative methods in public health: a field guide for applied research. 2nd ed. San Francisco: Jossey-Bass; 2005.

40. Ministry of Health and Child Care, UNICEF. National Baby Friendly Hospital Initiative (BHFI) strategic Plan In. Harare: Ministry of Health and Child Care, Zimbabwe; 2018.

41. Chagwena DT, Mugariri FM, Maunze L, Chigumira A. Parent's empowerement campaign to suport breastfeeding through workplace lactation support initiatives in Zimbabwe. J Hum Lact. 2017;33(4):794-5.

42. Ministry of Health and Child Care: Barriers and facilitators of optimal Infant and Young Child Feeding in Zimbabwe: Beliefs, influences and practices. Ministry of Health and Child Care; 2012

43. Ministry of Health and Child Care: Zimbabwe National Health Strategy 2016-2020 In. Causeway, Harare; 2016.

44. Arnold LD. Global health policies that support the use of banked donor human milk: a human rights issue. Int Breastfeed J. 2006;1:26.

45. Meier P, Patel A, Esquerra-Zwiers A. Donor human milk update: evidence, mechanisms, and priorities for research and practice. J Pediatr. 2017; 180:15-21.

46. Pérez LMaM J. Community health workers: social justice and policy advocates for community health and well-being. Am J Public Health. 2008, 98(1):11-4.

47. Jang HL, Cho JY, Kim M-J, Kim EJ, Park EY, Park SA, et al. The experience of human milk banking for 8 years: Korean perspective. J Korean Med Sci. 2016;31(11):1775-83.

48. Esquerra-Zwiers A, Rossman B, Meier P, Engstrom J, Janes J. Patel a: "It's somebody else's milk": unraveling the tension in mothers of preterm infants who provide consent for pasteurized donor human milk. J Hum Lact. 2016; 32(1):95-102.

49. Choto RG. Breastfeeding: breast milk banks and human immunodeficiency virus. Cent Afr J Med. 1990;36(12):296-300.

50. Baumer $\mathrm{JH}$. Guidelines for the establishment and operation of human milk in the UK. Arch Dis Childhood - Education Pract. 2004;89(1):29.

51. National Institute for Health and Clinical Excellence. Donor breast milk banks: the operation of donor milk bank services. High Holborn, London: National Institute for Health and Clinical Excellence; 2010

52. Young SL, Mbuya MN, Chantry CJ, Geubbels EP, Israel-Ballard K, Cohan D, Vosti SA, Latham MC. Current knowledge and future research on infant feeding in the context of HIV: basic, clinical, behavioral, and programmatic perspectives. Adv Nutr. 2011;2(3):225-43.

53. UNICEF. The state of WASH financing in eastern and southern Africa: Zimbabwe country level assessment. In. Nairobi, Kenya: UNICEF Eastern and Southern Africa regional office; 2019.

54. Raiten DJ, Steiber AL, Hand RK. Executive summary: evaluation of the evidence to support practice guidelines for nutritional care of preterm infants-the pre-B Project. Am J Clin Nutr. 2016;103(2):599s-605s.

\section{Publisher's Note}

Springer Nature remains neutral with regard to jurisdictional claims in published maps and institutional affiliations.

Ready to submit your research? Choose BMC and benefit from:

- fast, convenient online submission

- thorough peer review by experienced researchers in your field

- rapid publication on acceptance

- support for research data, including large and complex data types

- gold Open Access which fosters wider collaboration and increased citations

- maximum visibility for your research: over $100 \mathrm{M}$ website views per year

At $\mathrm{BMC}$, research is always in progress.

Learn more biomedcentral.com/submissions 